\title{
To help patients control asthma the clinician must be a good listener and teacher
}

Despite the fact that our understanding of asthma and its therapy has grown significantly over the last 20 years, there is ample evidence that asthma is not well controlled in many patients. Surveys in British schools have shown that as many as $50 \%$ of children who exhibit chronic symptoms of asthma are either undiagnosed or undertreated. ${ }^{12}$ Hospital admissions and visits to the emergency department, which largely reflect failures of primary preventive care for asthma, are abundant and increasing in many countries. ${ }^{3}$ Recent studies with computerised chronolog devices that record the exact time of each actuation of a metered dose inhaler show that compliance with asthma treatment regimens is even worse than previously thought. ${ }^{45}$ Furthermore, surveys of both children and adult sufferers indicate that emotional distress caused by asthma is common in both the patient and other family members. ${ }^{6-8}$

How can asthma be bètter controlled? Firstly, education is needed to help members of the public recognise asthma symptoms and encourage sufferers to seek informed medical care. Secondly, professional education is needed to help all health care providers understand and use state of the art asthma therapy in caring for their patients. Thirdly, patient education is needed to help patients and their families learn that they can manage asthma effectively and, in most cases, live active lives with little interference from symptoms. National asthma campaigns or education programmes in several countries have begun to address these problems through publication of asthma guidelines such as the International Consensus Report and other educational initiatives. There are, however, some significant barriers to changing both professional and patient behaviour that require new approaches to patient education and clinical care.

Patients need to be able to follow instructions outside the clinic and comply with treatment recommendations. One major barrier to achieving this is that patient education is often thought of as the one way transfer from clinician to patient of asthma information and skills such as the use of metered dose inhalers (MDI) and peak flow meters. While this aspect of education is important, learning such skills is only one part of a more comprehensive challenge facing asthmatic patients and their families. Studies of how patients with asthma respond to their illness suggest that they face three broader tasks that have consequences for its control..$^{6-8}$

They must first decide what asthma is and what it means to them, or about them, on a very personal level. Most new asthma patients or family members quickly develop intense feelings or beliefs about the condition which affect their motivation to adhere to the therapeutic plan. These feelings may include anger, self-blame, fear, a lessened sense of self-esteem, frustration at activity limitations and, for some, refusal to accept the diagnosis of asthma. Many have inaccurate beliefs about the origin or prognosis of asthma-for example, they may think it is caused by psychological factors or is a sign of vulnerability to illness in general. Other patients have serious reservations about taking medicines, especially on a daily basis, fearing side effects, addiction, or ineffectiveness of the prescription. Most patients initially view asthma as episodic rather than chronic, and this view makes it hard for them to understand and follow instructions to take preventive medication even when free of symptoms. In brief, patients develop beliefs about asthma which have powerful, but not necessarily helpful, effects on their attitudes towards health care, their goals for treatment, and their willingness and ability to control asthma. Such beliefs are often hidden from clinicians because pressure of time or the technical atmosphere of the clinical visit work against holding the kind of discussion needed to uncover them. The first challenge for the clinician, then, is to discover what the patient's knowledge, beliefs and feelings about asthma are, to reinforce those that are appropriate and accurate, and to begin the process of persuading the patient to change those that are not.

The second task for patients is the acquisition of information and skills needed to prevent and control asthma, which also entails developing the confidence to use these skills appropriately. This task includes recognising and responding to symptoms of asthma, understanding the purposes of different types of medicines and learning to use them correctly, and making appropriate decisions about when to seek emergency care. Although these aspects of patient education have received more attention from health care providers than any others, research suggests that many patients emerge from their contacts with clinicians ill prepared to carry out these elements of the treatment plan. ${ }^{6}$ Patients often fail to use medicines promptly once symptoms begin, and frequently stop using them too soon after remission. Many patients do not know how to decide when emergency care is needed, and the resulting anxiety adds to the psychic burden of managing asthma. ${ }^{7}$ Medications are often administered incorrectly by patients: two recent surveys showed that more than two out of three patients with asthma did not use MDIs properly. ${ }^{910}$ The correct use of an MDI is complex and is often not mastered by clinicians themselves. A recent study at a teaching hospital in New York found that paediatric residents, when asked to demonstrate inhaler technique, omitted or incorrectly performed $34 \%$ of seven key steps. ${ }^{11}$ The most common errors were failure to hold one's breath for at least five seconds (54\%), failure to shake the MDI before use (48\%), failure to exhale before $\mathrm{MDI}$ use (40\%), and actuating the MDI more than once during a single breath $(29 \%)$. These findings suggest that clinicians need better training themselves in the key skills needed for asthma management, as well as training in effective methods for teaching these skills to patients.

The third task that patients must learn is to manage key relationships so that both patient and family can live normal, active lives. For parents of children with asthma this means learning to talk with school teachers to get support for carrying out the child's treatment plan at school, or managing family relationships to minimise disruption of activities or relationships with siblings. ${ }^{6}$ For children it means learning to explain asthma to peers and overcome teasing or exclusion from games. ${ }^{12}$ For adults with asthma it may involve talking with employers about controlling environmental irritants and using asthma medicines in the workplace. These issues are often critical to the success of a preventive treatment strategy, yet they are rarely addressed by clinicians unless patients bring them up. In the UK, the National Asthma Campaign provides materials to help schools and employers develop appropriate policies about asthma. These include the leaflet Asthma in the workplace for per- 
sonnel and occupational health departments, and sample drafts of school policy on asthma and letters to parents.

The broad scope of issues that concern patients with asthma, and their potential for blocking constructive efforts to manage the disease, suggests that an alternative approach to treatment and patient education is needed. Research indicating that only about $50 \%$ of patients take medications as prescribed supports the idea that a narrow focus on teaching patients to comply with the prescribed treatment regimen is not very effective. ${ }^{13}$ The problem with the conventional view of compliance is that it assumes patients will ignore their own beliefs and goals to follow the clinician's treatment recommendations. There is a growing recognition that clinicians need to foster open communication and the development of an explicit partnership or alliance with the patient to address the full range of problems faced by asthma sufferers. In this partnership the patient is encouraged to teach the clinician how asthma affects key aspects of his or her life, and the clinician teaches the patient how to control asthma so that these limitations can be overcome. Information and concerns from both sides must be shared and a treatment plan negotiated that the patient is willing and able to follow. Ultimately the goal is to help the patient and family accept the diagnosis, develop the knowledge and skill to manage asthma in a way that is realistic to daily life, and be motivated to take actions that lead to full, unrestricted lives.

How can busy clinicians accomplish all this during brief outpatient visits? Research suggests that several approaches are effective, including changes in the way the clinical relationship is established and developed, and use of patient education resources outside the clinician's surgery.

\section{Strategies for clinical visits}

There are several strategies clinicians can use during an outpatient visit to establish a partnership and encourage active participation by patients. Firstly it is important to ask the patient and family members early in each visit what their immediate concerns about asthma and the medications are to identify the key beliefs and feelings that influence acceptance of the diagnosis and the resolve to follow the therapeutic plan. In a study of a general paediatric outpatient practice Korsch and colleagues found that, when the mothers' primary concerns or fears were not discussed with the doctor early in the visit, they were unable to remember the doctor's advice during an exit interview a few minutes later. ${ }^{14}$ Open ended questions such as "What is your biggest worry about asthma?" that cannot be answered with an unrevealing "yes" or "no" are best for bringing these concerns to light. Because most patients with asthma have concerns about taking medications, permissive questions such as "Many patients tell me they are worried about asthma medicines. What do you worry about?" are also likely to bring out important feelings or beliefs. ${ }^{15}$ By asking such questions, listening carefully, and responding thoughtfully to the specific concerns mentioned, the clinician can relieve anxiety, correct inappropriate beliefs, and tailor teaching and recommendations to the patient's immediate needs. Most importantly, they can convey the message that this is a relationship where questions and concerns are welcomed.

Secondly, it is essential to agree on goals of therapy that reflect both how the patient wants to live and what the clinician recognises as medically optimal. Research on health beliefs has shown that patients' goals for treatment often differ from those of clinicians. ${ }^{16}$ For example, a physician may focus on the goal of improving forced expiratory volume in one second to optimal levels while an adolescent patient may only want to be able to play football without coughing. If goals are not discussed, neither party will know what the other wants or expects. The focus should be on what patients want from treatment. If the clinician's and patient's goals conflict, it is preferable to agree to pursue the latter, since these are more likely to motivate the patient. Clinicians may be able, however, to modify patients' goals through the process of education. Many patients aim too low, having grown used to frequent cough or the feeling of breathlessness. ${ }^{17}$ By teaching such patients that they can control asthma so that uninterrupted sleep and vigorous activity without symptoms are possible, clinicians may be able to greatly improve the patient's quality of life.

Thirdly, clinicians can help patients to develop confidence that they can control asthma by praising positive actions they take and encouraging them to believe that they can master the skills required to prevent and treat asthma episodes. Research in health psychology indicates that increasing the self-confidence of patients that they can successfully perform challenging tasks will increase the frequency and persistence of their efforts to do so. ${ }^{18}$

Establishing partnerships with patients, along with of teaching them key information and skills, requires effec- 옥 tive use of time and other educational resources. Once the partnership is established the process of education can be managed by spreading it over a series of visits. It may be helpful to schedule one longer session and invite other family members to attend, thus allowing more time to explore beliefs and goals, and greater opportunity for teaching. In the United States, the National Asthma Education Program has developed a clinician's guide for teaching patients about asthma that includes brief lessons with patient handouts designed for use over a series of visits. ${ }^{19}$

Referral of patients to other sources of asthma education is an effective way of supplementing the teaching carried out by the clinician. These resources include written and audiovisual materials, and organised health education programmes for patients and family members.

\section{Asthma health education programmes}

In the past decade there has been substantial research into the behavioural aspects of asthma which has led to the development of health education programmes to 은 teach patients and their families to manage the condition $D$ more effectively. These programmes are not intended to replace education provided by clinicians during routine $\bar{N}$ clinic visits, but rather are designed to supplement and extend it. Many of the programmes have been evaluated $N$ with controlled research designs and found to be effective $\omega$ in improving asthma management skills, ${ }^{1220-28}$ reducing morbidity or use of emergency health care services, ${ }^{12} 2123-28$ and improving quality of life. ${ }^{1220-23252728}$

The programmes all rely on more extensive interactions between patients and health care professionals than is usually possible in a visit to the clinic. Some pro- $\mathbb{D}$ grammes involve one-to-one teaching for children and $\mathbb{\Phi}$ family members, ${ }^{232930}$ or adult patients, ${ }^{25} 263031$ and can be used easily in outpatient or hospital settings. These programmes are usually integrated closely with the patient's medical care and can be tailored to the needs of a specific patient or family.

In group health education programmes for children, ${ }^{1220-243233}$ or adults, ${ }^{252728}$ groups of $10-12$ patients usually work together with a single educator in a series of 3-6 sessions held weekly or biweekly. Most programmes are designed for use in health care organisations but can also be conducted in non-medical settings. Several pro- 
1 Dealing with fears and other feelings about asthma.

2 Providing basic information about the pathophysiology of asthma.

3 Administering prescribed medication correctly and managing anticipated adverse effects.

4 Responding to symptoms of asthma:

Recognising early signs and symptoms.

Initiating prescribed therapy promptly.

Remaining calm and avoiding panic.

Recognising the need for emergency care.

5 Reducing exposure to known triggers of asthma.

6 Normalising the physical and social activities of children with asthma.

7 Solving problems about school and asthma.

8 Communicating effectively with physicians and other health care personnel.

Adapted with permission from Mellins. ${ }^{34}$

grammes are designed specifically for use in schools..$^{120}$ The sessions, which last for 1-2 hours, follow a curriculum (see table for an example from a programme for children and their families ${ }^{6434}$ ) but use teaching methods centred on the patient to identify the problems which participants experience in managing asthma, and encourage them to develop solutions in the group and to try them out at home.

Working with patients and families in groups has several important advantages. Firstly, because asthma affects only about $5 \%$ of the population, many patients feel isolated. Sharing experiences in a group gives people a sense that they are not alone, which is itself a therapeutic experience, and makes the process of identifying beliefs and emotional reactions to asthma far easier. Secondly, research in many fields shows that interaction among peers can exert a powerful influence on behaviour change. Hearing other patients like oneself recount experiences that led them to accept the value of daily antiinflammatory therapy or thorough environmental control practices is often far more effective in motivating change than the advice of an expert. Thirdly, the problem solving approach combined with group continuity gives participants the chance to try potential solutions at home and share the results with other members of the group. Strategies that do not work well can be analysed and revised in an atmosphere of understanding and support. Solutions that prove successful can be shared and praised, which reinforces the confidence and motivation of all the members of the group to control asthma.

Effective, tested materials for educating patients are now available for use by individual clinicians and by health or voluntary organisations. Several programmes ${ }^{22-2432}$ may be obtained by contacting the National Asthma Ėducation Program, NHLBI Information Center, Bethesda, Maryland 20824-0105, USA, and information about others may be obtained by contacting the investigators. For Europeans a major conference on asthma education is to be held in London in February $1994^{\star}$ to look at issues such as which educational strategies are successful in fostering self-management, and how clinicians can make the best use of teaching opportunities in outpatients clinics, consulting rooms, or hospital emergency departments.

The challenge now is to recognise that establishing patient-provider partnerships is an essential step in helping patients to learn to manage chronic illnesses like asthma. By following this approach to working with patients and their families in visits to the clinic and in expanded educational opportunities, clinicians can foster better management of asthma that leads to reduced morbidity and use of emergency health care services, and to improved quality of life for patient, family, and clinician. D EVANS Columbia University, College of Physicians and Surgeons, Pediatric Pulmonary Division, 630 West 168th Street, New York, NY 10032, USA

Reprint requests to: Dr D Evans

1 Speight ANP, Lee DA, Hey EN. Underdiagnosis and undertreatment of asthma in childhood. $B M \mathcal{F} 1983 ; 286: 1253-6$.

2 Hill RA, Standen PJ, Tattersfield AE. Asthma, wheezing, and school absence in primary schools. Arch Dis Child 1989;64:246-51.

3 Buist AS, Vollmer WM. Reflections on the rise in asthma morbidity and mortality. FAMA 1990;264:1719-20.

4 Rand CS, Wise RA, Nides M, Simmons MS, Bleecker ER, Kusek JW, et al. Metered-dose inhaler adherence in a clinical trial. Am Rev Respir Dis 1992;146:1559-64.

5 Spector SL, Kinsman R, Mawhinney H, Siegel SC, Rachelefsky GS, Katz RM, et al. Compliance of patients with asthma with an experimental aerosolized medication: implications for controlled clinical trials. $f$ Allergy Clin Immunol 1986;77:65-70.

6 Clark NM, Feldman CH, Freudenberg N, Millman EJ, Wasilewski Y, Valle I. Developing education for children with asthma through study of self-management behavior. Health Educ $Q$ 1980;7:278-96.

7 Nocon A, Booth T. The social impact of asthma. Family Pract 1991;8 $37-41$.

8 Sibbald B. Patient self care in acute asthma. Thorax 1989;44:97-101.

9 Kemp JP, Meltzer EO. Beta 2 adrenergic agonists: oral or aerosol for the treatment of asthma? $f$ Asthma 1990;27:149-57.

10 King D, Earnshaw SM, Delaney JC. Pressurised aerosol inhalers: the cost of misuse. Br f Clin Pract 1991;45:48-9.

11 Mas JC, Resnick DJ, Firschein DE, Feldman BR, Davis WJ. Misuse of metered dose inhalers by house staff members. Am $\mathcal{f}$ Dis Child 1992; 146:783-5.

12 Evans D, Clark NM, Feldman CH, Rips JL, Kaplan DL, Levison MJ, et al. A school health education program for children with asthma aged 8-11 years. Health Educ $Q$ 1987;14:267-79.

13 Ley P. Communicating with patients: improving communication, satisfaction and compliance. New York: Chapman and Hall, 1988:53-71.

14 Korsch BM, Gozzi EK, Francis V. Gaps in doctor-patient communications. 1. Doctor-patient interaction and patient satisfaction. Pediatrics 1968;42:855-71.

15 Partridge MR. Self-care plans for asthmatics. Practitioner 1991;235 715-21.

16 Janz NK, Becker MH. The health belief model: a decade later. Health Educ $Q$ 1984;11:1-47.

17 Burdon JGW, Juniper EF, Killian KJ, Hargreave FE, Campbell EJM. The perception of breathlessness in asthma. Am Rev Respir Dis 1982;126: 825-8.

18 Ewart CK. Social action theory for public health psychology. Am Psychol 1991;46:931-46.

19 National Asthma Education Program. Teach your patients about asthma: clinician's guide. NIH Publication No. 92-3737. Bethesda, Maryland: NHLBI Information Center.

20 Parcel GS, Nader PR, Tiernan K. A health education program for children with asthma. $\mathcal{F}$ Dev Behav Pediatr 1980;1:128-32.

21 Lewis CE, Rachelefsky G, Lewis MA, de la Sota A, Kaplan M. A randomized trial of ACT (asthma care training) for kids. Pediatrics $1984 ; 74: 478-86$

22 Wilson-Pessano SR, McNabb WL. The role of patient education in the management of childhood asthma. Prev Med 1985;14:670-87.

$23 \mathrm{McNabb}$ WL, Wilson-Pessano SR, Hughes GW, Scamagas P. Self-management of children with asthma: Air Wise. Am $\mathcal{f}$ Public Health 1985;75:1219-20.

24 Clark NM, Feldman $\mathrm{CH}$, Evans D, Levison MJ, Wasilewski $\mathrm{Y}$, Mellins RB. The impact of health education on frequency and cost of health care utilization by low income children with asthma. $f$ Allergy Clin Immunol 1986;78:108-15.

25 Bailey WC, Richards JM, Brooks M, Soong S, Windsor RA, Manzella $B A$. A randomized trial to improve self-management practices of adults with asthma. Arch Intern Med 1990;150:1664-8.

26 Mayo PH, Richman J, Harris HW. Results of a program to reduce admissions for adult asthma. Ann Intern Med 1990;112:864-71.

27 Bolton MB, Tilley BC, Kuder J, Reeves T, Schultz LR. The cost and effectiveness of an education program for adults who have asthma. f Gen Intern Med 1991;6:401-7.

28 Wilson SR, Scamagas P, German DF, Hughes GW, Lulla S, Coss S, et al. A controlled trial of two forms of self-management education for adults with asthma. Am $\mathcal{F}$ Med 1993;94:564-76.

29 Taggart VS, Zuckerman AE, Sly RM, Steinmueller C, Newman G O'Brien RW, et al. You can control asthma: evaluation of an asthma education program for hospitalized inner-city children. Patient Education and Counseling 1991;17:35-47.

30 Chariton I, Charlton G, Broomfield J, Mullee JA. Audit of the effect of a nurse run asthma clinic on workload and patient morbidity in a general practice. Br f Gen Pract 1991;41:227-31.

31 Beasley R, Cushley $M$, Holgate ST. A self-management plan in the treatment of adult asthma. Thorax 1989;44:200-4

32 Creer TL, Backiel M, Burns KL, Leung T, Marion RJ, Micklich DR, et al. Living with asthma, part I. Genesis and development of a self-management program for childhood asthma. $\mathcal{F}$ Asthma 1988;25:335-62.

33 Hindi-Alexander MC, Cropp G. Evaluation of a family asthma program f Allergy Clin Immunol 1984;74:505-10.

34 Mellins RB. Patient education is key to successful management of asthma. f Respir Dis 1989;10:S47-52. 